\title{
Arthroscopic Management of Acute Traumatic Primary Anterior Shoulder Dislocation
}

\author{
KHALID A. SHOHAYEB, M.D.*; NASEF M. NASEF, M.D.**; AMR RASHWAN, M.D.*; \\ BAHAAALDINE S. ABD EL-WAHAB, M.Sc.*; MOHAMED H.E. ABORAS, M.Sc.**; \\ REDA A.A. SHETA, M.Sc.*; MOEMEN SEIF, M.Sc.** and OMAR A. FATHY, M.Sc.** \\ The Department of Orthopedic Surgery, Student Hospital* and Faculty of Medicine**, Cairo University
}

\begin{abstract}
Background: Glenohumeral joint is the most mobile and most commonly dislocated joint in the human body. The patient's age at the time of injury is inversely related to the incidence of dislocation recurrence rate. Recurrence rate in athletes younger than 20, may be as high as $90 \%$. Arthroscopic stabilization is usually successful in preventing the recurrence of shoulder dislocations leads to reduced recurrence, improved functional outcome

Aim of Study: The aim of this study is to asses the benefits of Bankart repair using suture anchors in treating patient with first time anterior traumatic shoulder instability.

Patients and Methods: This prospective study was performed on 30 patients having anterior primary shoulder dislocation. All cases were managed by arthroscopic repair of the anterior labral lesion using suture knotted anchors.

Results: Patients were assessed pre and post operatively by modified Rowe scale and ASES (American shoulder and Elbow disability system).

Conclusion: Primary arthroscopic repair for first-time traumatic anterior shoulder dislocation provided satisfactory functional outcomes and improved quality of life. Primary arthroscopic stabilization can be considered best treatment option in patients younger than 30 years with first time shoulder dislocation.
\end{abstract}

Key Words: Shoulder dislocation - Bankart lesion - Anchors.

\section{Introduction}

THE most common mode of this injury is the anterior dislocation when the head of humerus dislocates anteriorly and medially in relation to its normal anatomical position. Following the first dislocation, chronic anterior instability of the glenohumeral joint might occur. The most common cause of shoulder instability is a traumatic injury,

Correspondence to: Dr. Khalid A. Shohayeb, The Department of Orthopedic Surgery, Student Hospital, Cairo University in $95 \%$ of all anterior shoulder dislocations. Patient age at the time of injury is the most important predicting factor for recurrence. Other risk factors include early return to competitive contact sports and poor compliance to rehabilitation program.

\section{Patients and Methods}

This study was performed on 30 patients having anterior primary shoulder dislocation. Patients were managed between 1/1/2013 till 1/6/2015 and all were done at Cairo university hospitals. All patients had a single episode of dislocation. Patients suffered the injury during participating in sports activities, eight patients during catching the arm from behind in handball playing, three patients during throwing, seven patients during lifting heavy weights and eight patients after a falling down in running activities and four patients experienced their injury during daily activities like falling on staircase. All cases were managed by arthroscopic repair of the anterior labral lesion using suture knotted anchors. Fourteen patients were done after one month of 1 st episode of dislocation and eight patients were done after three months while six patients were done after 6 months and two patients had surgery after eight months of 1 st dislocation. Inclusion criteria's include: Acute traumatic primary anterior shoulder dislocation, young adult patients younger than 40 years, MRI evidence of Bankart lesion, persistence of pain and instability in a shoulder with history of single dislocation, athletic patients. Exclusion criteria's were: Age above 40 years, recurrent anterior shoulder dislocations, associated comorbidity and unfitness for surgery, epileptic patients unless controlled for "1" year, prior shoulder girdle fracture, bony bankart lesion, absence of bankart lesion in the MRI. 
Surgical technique \& post-operative management:

All patients received general anesthesia. All patients were positioned in beach chair position with head tightened to the beach chair head piece. Anesthesia tube was tilted to the contralateral side. Elastic bandages were wrapped around both legs. Examination under general anaesthesia with provocative tests was done for all patients before starting the procedure. After sterile drapping, two portals named the posterior portal and the anterior portal were done.

The posterior portal is located approximately $2 \mathrm{~cm}$ inferior and medial to the posterolateral corner

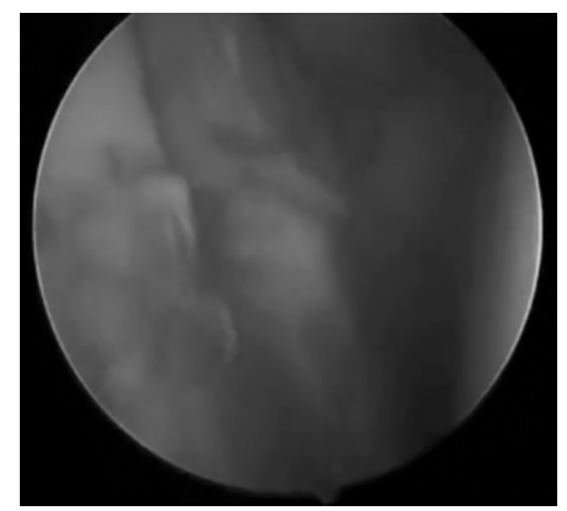

Labral lesion

The first anchor is inserted through the most inferior part of inferior glenohumeral ligament. A bird pea is used to pull the anchor robe through the tissue labrum, while tying a sliding knot, the limb that passes through the tissues must be the post to deliver the knot away from the articular

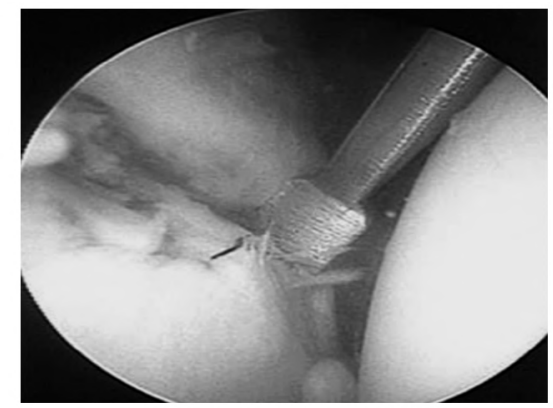

Rasping the edges of glenoid of the acromion at the posterior "soft spot". An anterior portal should be placed as close as possible to the superior edge of the subscapularis tendon. The arthroscope enters the joint in the interval between the infraspinatus and teres minor muscles. Standard diagnostic shoulder arthroscopy was performed as a first step in all cases to confirm the pathology (Bankart lesion). Rasping the edge of the glenoid. Identification the site of anchor insertion (1-3-5 clock) right shoulder \& (7-9-11 clock) on the left shoulder, few millimeter from the glenoid edge angled to avoid damage to the articular surface.

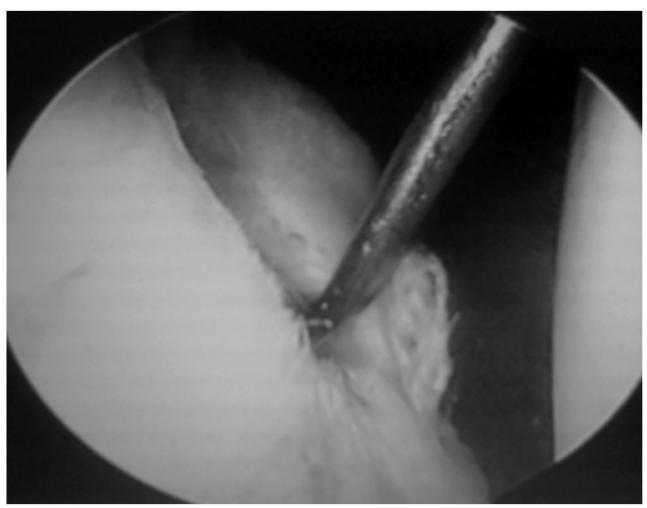

Identification of labrum lesion

surface. A sliding knot is made and slided down the cannula by a knot pusher. Two counterrunning (half hitches) knots complete the suture. According to the length of the labral detachment this procedure must be repeated two or three times.

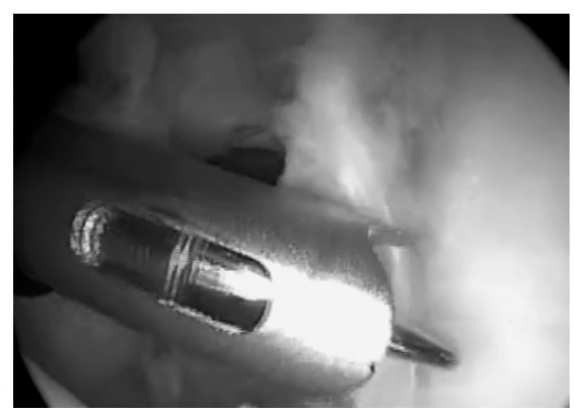

Insertion of first anchor

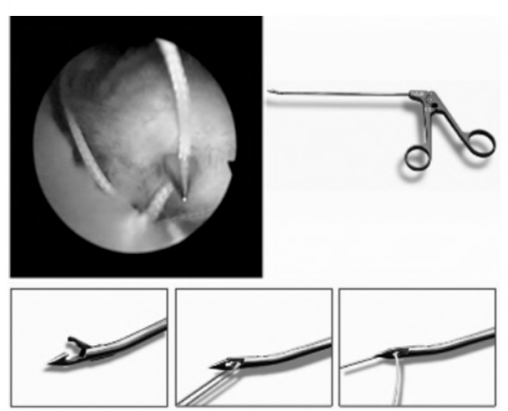

Bird peak anchor pulling

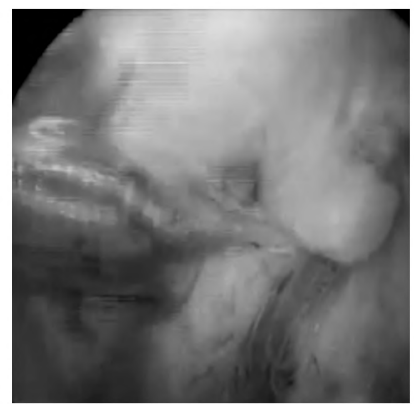

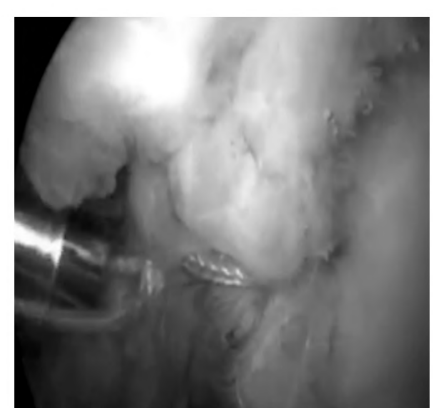

Formation of sliding knot 
All cases were done with knotted suture anchor. The number of anchors used ranged between 2-3 anchors according to the capsulo-labral length. Twenty-four cases were managed by 2 anchors, 4 cases by 3 anchors and one case managed by 4 anchors. Post-operatively all cases were given analgesics (NSAID) for pain reduction and antibiotics 3 rd generation cephalosporins, immobilization was carried out for three weeks, day and night using arm pouch sling with abdominal belt.

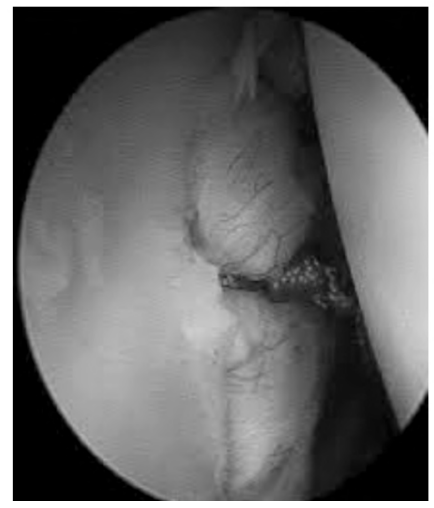

Final anchor placement

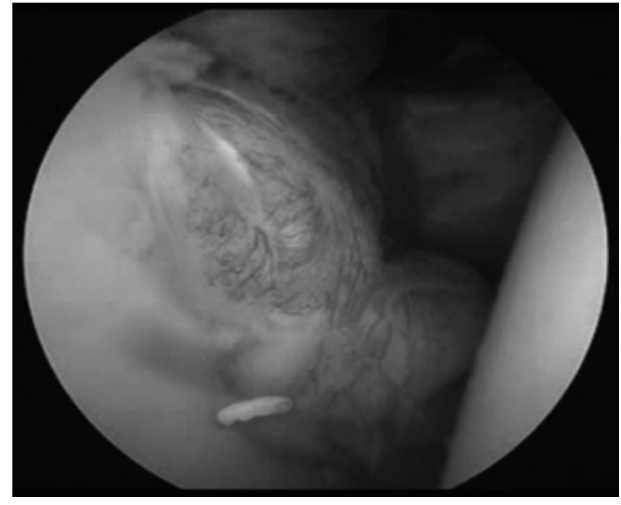

Full repaired labrum

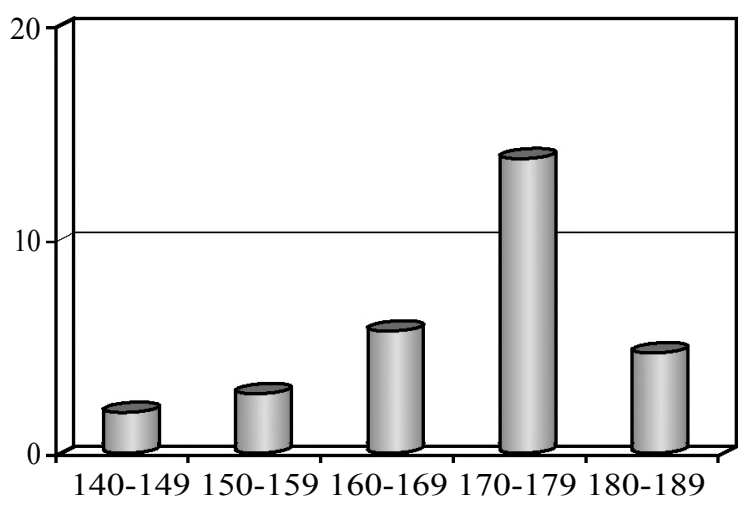

Fig. (1): Range of elevation.

External rotation at side: The range of external rotation varied between 30 up to 70 .

Table (2): Range of external rotation.

\begin{tabular}{lcc}
\hline Range of external rotation & Number of patients & Percentage \\
\hline $30-39$ & 2 & 6.6 \\
$40-49$ & 3 & 10 \\
$50-59$ & 5 & 16.6 \\
$60-69$ & 14 & 46.6 \\
70 or more & 7 & 23.3 \\
\hline
\end{tabular}
of motion including elevation, external rotation and internal rotation.

Elevation: The range of elevation varied between 140 up to 180 . The average postoperative forward elevation was 170 .

Table (1): Range of elevation.

\begin{tabular}{lcc}
\hline Range of elevation & Number of patients & Percentage \\
\hline $140-149$ & 2 & 6.6 \\
$150-59$ & 3 & 10 \\
$160-169$ & 6 & 20 \\
$170-179$ & 14 & 46.6 \\
180 or more & 5 & 16.6 \\
\hline
\end{tabular}

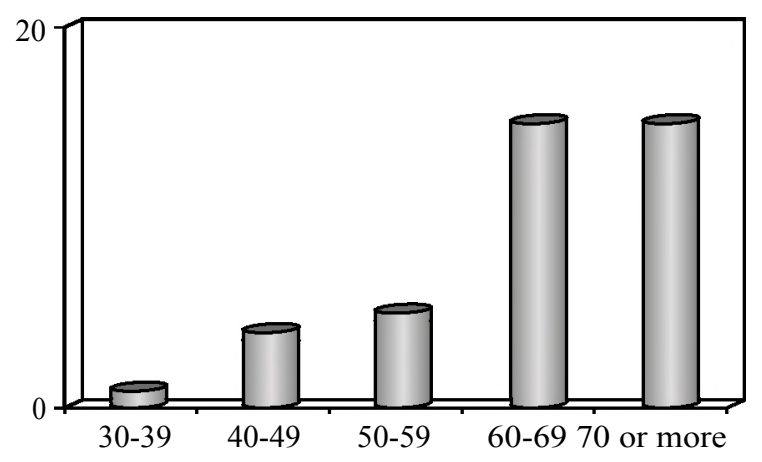

Fig. (2): Range of elevation. 
Internal rotation hand to back: The internal rotation range varied between $\mathrm{T} 4$ up to $\mathrm{L} 2$.

\begin{tabular}{lcl}
\multicolumn{4}{l}{ Table (3): Range of internal rotation. } \\
\hline Range of internal rotation & Number of patients Percentage \\
\hline T4 & 7 & 23.3 \\
T5 & 6 & 20 \\
T6 & 3 & 10 \\
T7 & 0 & 0 \\
T8 & 1 & 3.3 \\
T9 & 7 & 23.3 \\
T10 & 0 & 0 \\
T11 & 2 & 6.6 \\
T12 & 0 & 0 \\
L1 & 3 & 10 \\
L2 & 1 & 3.3 \\
\hline
\end{tabular}

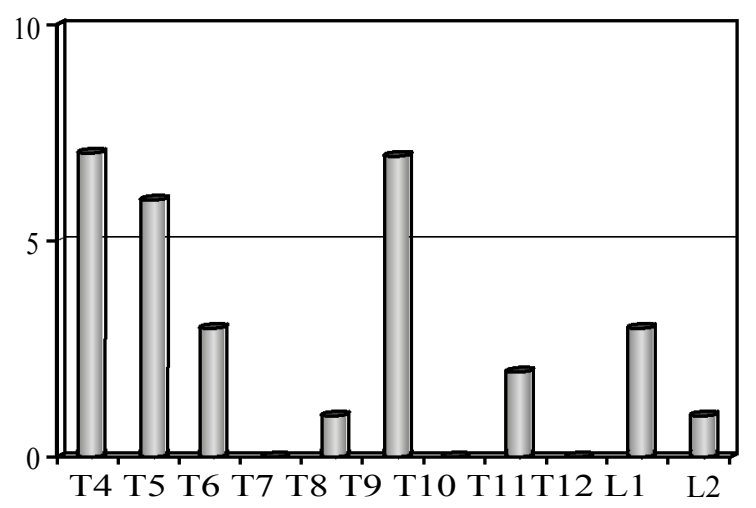

Fig. (3): Range of internal rotation.

Functions and sports activities: All patients of the study returned to their work. Twenty six patients of the study were participating in sports activities prior to injury. All of them were able to practice sports again but six out of them not as the same as previously. Two $(6 \%)$ patients had no limitation at work but were not able to practice work and sports. Two patients $(6 \%)$ had moderate limitation at work.

Recurrence of instability: None of the patients had any signs of instability after operation. Ant drawer test was done pre-operative and post-operative to compare. Infection one patient complained of infection at one of the sutures and was treated by 3 rd generation antibiotics for another 2 weeks. One patient complained of squeaking and upon doing X-ray, it revealed loose anchor but the patient refused to do any surgical intervention.

The overall average score by modified Rowe $\sim \mathrm{s}$ score was 41 points pre-operatively and 92.8 postoperatively out of 100 points in the studied 30 patients. Post-operatively excellent results $(90 \%)$ or more were obtained in 22 cases $(74 \%)$, good results $(70-89 \%)$ in 7 cases $(23 \%)$ fair results (40-
$69 \%$ ) in one case (3\%). American Shoulder and Elbow Disability System (ASES): Pre-operative score was (62.2) and postoperative average score was (93.6), excellent results were obtained in $(93.3 \%)$ of cases, good results obtained in $(3.3 \%)$ of cases and fair result obtained in $(3.3 \%)$ of cases.

\section{Discussion}

In this study we performed 30 cases of primary anterior shoulder dislocation. All had Bankart lesion and all were operated upon using suture anchors. The age ranged between 18 and 36 years. The follow-up period ranged between 10 and 30 months with an average of 20 months, we applied the modified Rowe's scoring system and ASES.

Post-operatively, according to Rowe's score excellent results $90 \%$ or more obtained in 22 cases (74\%), good results $(70-89 \%)$ obtained in 7 cases $(23 \%)$, fair results (40-69\%) obtained in one case (3\%) and according to ASES score excellent results were obtained in $(93.3 \%)$ of cases, good results obtained in $(3.3 \%)$ of cases and fair result in $(3.3 \%)$ of cases. The overall average score was (41) points preoperatively and (92.8) post-operatively out of 100 points according to Rowe's score and the overall average score was (93.6) according to ASES score in the studied 30 patients.

All patients of the study returned to their work. Twenty six patients were participating in sports activities prior to injury. All of them were able to practice sports again but six out of them not as the same as previously. Two patients had no limitation at work but were not able to practice sports. Two patients had moderate limitation at work. Average points were 42.1. The overall functional activities improved from 28.5 points preoperatively to 42.1 post-operatively of 50 points according to Rowe Score.

In a study by Sang-Jin in 2016, the study included 33 patients who underwent arthrosopic bankart repair after first time shoulder dislocation before the age of 30 years. There were 89 agematched patients who were treated arthroscopically for recurrent dislocation included as a control group. Results revealed increased anterior glenoid erosion more frequently in the recurrent dislocation group and a significant difference in the failure rate after operation between the 2 groups. In the first-time dislocation group, one patient had redislocation and none showed positive apprehension. In the recurrent dislocation group, 6 patients had redislocation and 10 patients had positive apprehension. Eight of 10 patients who showed positive apprehension had either anterior labral periosteal 
sleeve avulsion lesions or anterior glenoid erosion. The patients' satisfaction with daily activities was significantly better in the first-time dislocation group (93.0 \pm 5.2$)$ than in the recurrent dislocation group $(82.7 \pm 7.2 ; p<.001)$. Conclusions: Primary surgical treatment for first-time traumatic anterior shoulder dislocation provided satisfactory functional outcomes and improved quality of life. Primary arthroscopic stabilization can be considered one of the treatment options in patients younger than 30 years with first-time shoulder dislocation to prevent further intra-articular injuries that may contribute to recurrence.

In another study published in 2016, a systematic review was performed. Fifteen articles including a total of 693 patients with 705 shoulders aged 18 years or younger. Of 411 shoulders, 293 (71.3\%) treated with a nonoperative approach experienced a redislocation compared with 55 of 314 shoulders $(17.5 \%)$ that received surgical treatment. The results showed that the recurrence rate was significantly lower in the surgical group compared with the nonoperative group. The recurrence rate is lower in patients undergoing surgical treatment.

In a study was performed by Chapus and published in 2015 , twenty one patients with initial anterior dislocation were included. All patients underwent arthroscopic Bankart repair within 30 days of dislocation. Patients were followed-up with clinical and radiological assessment. There were 5 recurrent dislocations $(25 \%)$ and 2 patients reported sensations of sublaxation. Mean rowe score was 86 . There was significant internal rotation deficit of one vertebral level between operated and contralateral shoulder. At 10 years follow-up, 3 shoulders $(15 \%)$ showed samilson grade 1 centered osteoarthritis. Conclusion: Early arthroscopic capsulo-labral repair by bankart repair in patients less than 25 years of age provided a low recurrence rate $(35 \%)$ compared to the literature, including dislocation (25\%) and sublaxation (10\%). Functional outcome was satisfactory and Osteoarthritis rate was low (15\% samilson grade 1$)$.

\section{Conclusion:}

Anterior traumatic shoulder instability is a common problem especially among the active young population. The timing of surgery is the key factor to prevent recurrence. Most authors agree that in athletes and young populations, surgery should be performed after the first episode because of high recurrence rate and to avoid further soft tissue or bony damage from subsequent dislocations. Advantages for early arthroscopic repair of labrum is to prevent further damage and to decrease recurrent episodes of dislocation thus decreasing the incidence of osteoarthritis may occur with dislocations, decrease morbidity and early return to working and sports level of activities.

\section{References}

1- DUMONT G., RUSSELL R. and ROBERTSON W.: Anterior shoulder instability: A review of pathoanatomy, diagnosis and treatment. Curr. Rev. Musculoskelet. Med., 4: 200-7, 2011.

2- FAAIZ ALI SHAH1 and WAQAR ALAM2: Shahab ud Din. Frequency of Recurrent Shoulder Dislocation After Primary Traumatic Anterior Dislocation Treated Non Operatively. International Journal of Clinical Medicine Research, 2 (4): 49-53, 2015.

3- HOVELIUS L.1 and RAHME H.2: Primary anterior dislocation of the shoulder: Long-term prognosis at the age of 40 years or younger. Knee. Surg. Sports. Traumatol. Arthrosc. X. Feb. Epub., 201, 2015.

4- KANE P.1, BIFANO S.M., DODSON C.C. and FREEDMAN K.B. PHYS: Approach to the treatment of primary anterior shoulder dislocation: A Review. Feb., 43 (1): 54 64, 2015.

5- KHIAMI F.1, GÉROMETTA A.2 and LORIAUT P.2 ORTHOP TRAUMATOL SURG RES.: Management of recent first-time anterior shoulder dislocations. Feb., 101 (1 Suppl): S51-7, 2015.

6- LONGO U.G., LOPPINI M., RIZZELLO G., CIUFFREDA M., MAFFULLI N. and DENARO: Management of primary acute anterior shoulder dislocation: Systematic review and quantitative synthesis of the literature. Arthroscopy, 30 (4): 506-22, 2014.

7- M. OLDS, 1K. DONALDSON, 1R. ELLIS and 2P. KERSTEN 3.: In children 18 years and under, what promotes recurrent shoulder instability after traumatic anterior shoulder dislocation? A systematic review and metaanalysis of risk factors. January, 17, 2016.

8- J. UHRING*, P.B. REY, S. ROCHET and L.OBERT.: Interest of emergency arthroscopic stabilization in primary shoulder dislocation in young athletes. Orthopaedics \& Traumatology: Surgery \& Research, 100S, S401-S408, 2014.

9- SANG-JIN SHIN, M.D.*, YOUNG WON K.O., M.D. and JUYEOB LEE, M.D.: Intra-articular lesions and their relation to arthroscopic stabilization failure I in young patients with first-time and recurrent shoulder dislocations. J. Shoulder. Elbow. Surg., 25: 1756-63, 2016.

10- OLDS M., ELLIS R., DONALDSON K., et al.: Risk factors which predispose first-time traumatic anterior shoulder dislocations to recurrent instability in adults: A systematic review and meta-analysis. B. J. Sports. Med., 49: 913-22, 2015

11- POLYZOIS I.1, DATTANI R.1, GUPTA R.1, LEVY O.1 and NARVANI A.A. 1.: Traumatic First Time Shoulder Dislocation: Surgery vs Non-Operative Treatment. Arch. Bone. Jt. Surg. Apr., 4 (2): 104, 2016.

12- PAGNANI M.J. and DOME D.C.: Surgical treatment of traumatic anterior shoul 9 der instability in American 
football players. J. Bone. Joint. Surg. Am., 84: 711-5, 2012.

13- PROVENSHER M.T., FRANK R.M. LECLERE L.E., METZGER P.D., RYUJJ. BERNARDSON A., ROMEO A.A., et al.: The Hil Sachs lesion: Diagnosis, classification, and management. JAM. Acad. Orthop. Surg., 20 (4): 242$52,2012$.

14- POLLOCK R.G., WANG V.M., BUCCHIERI J.S., et al.: Effects of repetitive subfailure strains on the mechanical behavior of the inferior glenohumeral ligament. J. Shoulder. Elbow. Surg., 9: 427-35, 2011.

15- RAMES R.D. and KARZEL R.P.: Injuries of the glenoid labrum. Ortho. Clin. North Am., 24 (1): 44-53, 2012.
16- ROBINSON C.M., SHUR N., SJARPE T. and RAY MURRAY: Injuries associated with traumatic anterior glenohumeral dislocations. J. Bone. Joint. Surg. Am., 94 (1): 18-26, 2012.

17- SPIEGL U.J.1, RYF C., HEPP P. and RILLMANN P.: Evaluation of a treatment algorithm for acute traumatic osseous Bankart lesions resulting from first time dislocation of the shoulder with a two year follow-up. BMC. Musculoskelet. Disord. Oct., 25, 14: 305, 2013.

18- SEDEEK S.M.1, BIN ABD RAZAK H.R., EE G.W. and TAN A.H.: First-time anterior shoulder dislocations: Should they be arthroscopically stabilised? Singapore. Med. J. Oct., 55 (10): 511-5, 2014.

\section{العلاج بإستخدام المنظار لحالات الخلع الأولى الكئ

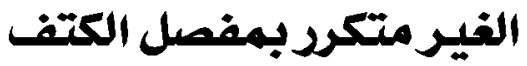

يعتبر مفصل الكتف هو أكثر مفصل معرض للخلع كونه ذو مجال حركى واسع وتعتبر حالات الخلع من الأمراض الثائعة لهذا المفصل خاصة أثثاء ممارسة الرياضة وخاصة لذهى الفئة العمرية الصفيرة.

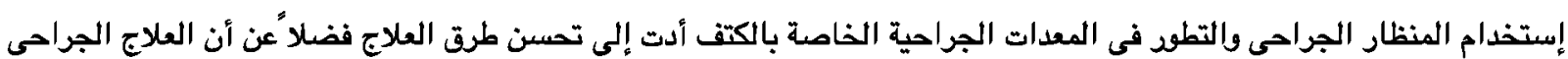

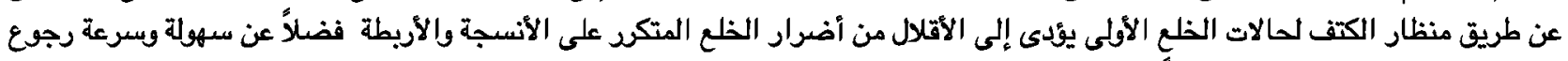

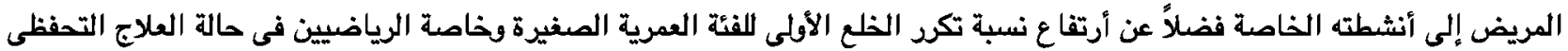

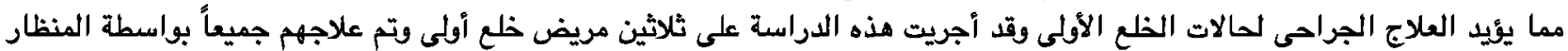

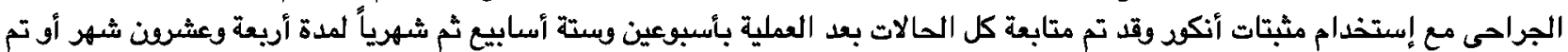

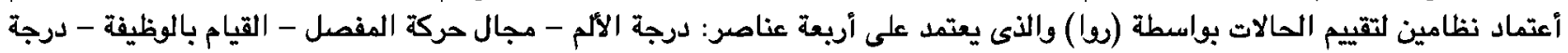

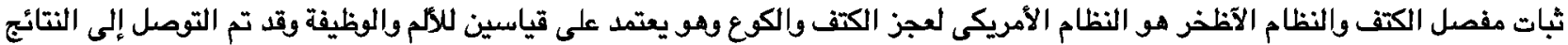

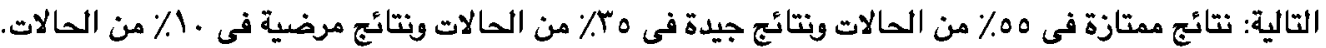

يظل لمنظار الكتف الجراحى مميزات أخرى منها قصر فترة الإقامة بالمستشفى وبسرعة بدء العلاج الطبيعى إن إستخدام المنظار الجراحى

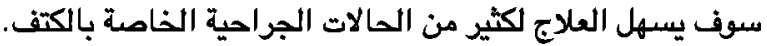

